\title{
Discrepancy between functional recovery and cutaneous silent period change in surgically treated degenerative cervical myelopathy: a prospective pilot study
}

\author{
Nobuaki Tadokoro $\mathbb{D}^{1} \cdot$ Katsuhito Kiyasu $^{1} \cdot$ Yusuke Kasai $^{1} \cdot$ Motohiro Kawasaki $^{1} \cdot$ Ryuichi Takemasa $^{1} \cdot$ \\ Masahiko Ikeuchi ${ }^{1}$
}

Received: 26 January 2019 / Revised: 3 June 2019 / Accepted: 4 June 2019 / Published online: 18 June 2019

(c) The Author(s), under exclusive licence to International Spinal Cord Society 2019

\begin{abstract}
Study design Exploratory research

Objectives Cutaneous silent periods (CSPs) that reflect the inhibitory spinal cord reflex, can sensitively detect spinal cord dysfunction, and contribute to the diagnosis of degenerative cervical myelopathy (DCM). However, CSP changes after DCM surgery related to functional improvement have not been reported.

Setting University hospital in Nankoku, Japan

Methods CSP recorded at four time points-before surgery, 3, 6, 12 months after surgery-were investigated in 31 hands of 16 DCM patients. CSPs were categorized as follows: normal, delayed onset latency, shortened duration, onset delay with shortened duration, and absent CSP. Myelopathic symptoms were evaluated by the Japanese Orthopaedic Association score (JOA score).

Results Normal CSPs were observed in five hands (16\%) before surgery and six hands (19\%) twelve months after surgery $(P>0.05)$. Either onset delay or shortened duration or both were observed in 18 hands $(58 \%)$ before surgery and 16 hands $(52 \%)$ twelve months after surgery $(P>0.05)$. Absent CSPs were observed in eight hands $(26 \%)$ before surgery and nine hands $(29 \%)$ twelve months after surgery $(P>0.05)$. Measured values of onset latency and duration also did not change throughout the study period $(P>0.05)$. On the other hand, JOA scores improved after surgery. $(P=0.003)$.

Conclusions CSP abnormalities persisted after surgery in most cases, indicating irreversible damage of the intramedullary reflex circuit. JOA score recovery without CSP recovery provides insight into postoperative neural recovery in DCM.
\end{abstract}

\section{Introduction}

Degenerative cervical myelopathy (DCM) is a leading cause of tetraparesis in older individuals [1]. The number of patients requiring surgical treatment is growing worldwide. Early diagnosis is important as pre-operative functional severity strongly influences post-operative functional recovery [2]. Magnetic resonance imaging (MRI) is useful for delineating spinal cord compression as well as intramedullary signal changes. Both findings contribute to

Nobuaki Tadokoro

tadokoro.nobuaki@kochi-u.ac.jp

1 Department of Orthopaedic Surgery, Kochi Medical School, Kochi University, Kochi, Japan diagnosis and surgical decision-making for DCM. However, morphological abnormalities do not necessarily correlate with clinical signs and symptoms [3]. Thus, additional functional diagnosis is needed for comprehensive patient management. The cutaneous silent period (CSP), which is a transient suppression of voluntary contraction of muscles, is generated by the inhibitory spinal reflex [4]. Abnormal CSPs reflect intramedullary pathology such as DCM and syringomyelia [5, 6]. Furthermore, abnormal CSPs are reportedly able to detect DCM, even if the severity of myelopathy is mild [6]. Therefore, as abnormal CSPs can contribute to an early detection of DCM, this provides a chance of an improved prognosis. However, whether CSP testing could reflect functional improvement after surgery remains unknown. The aim of this study is to elucidate the post-operative CSP changes associated with functional improvement. 


\section{Methods}

CSPs were recorded from the index fingertip and abductor pollicis brevis (APB) muscle as the stimulating site and recording site, respectively. Single shocks were delivered using a pair of ring electrodes. Electric stimuli were square waves of $0.2 \mathrm{~ms}$ in duration with stimulus intensities 20 times stronger than the sensory threshold. The sensory threshold was defined as the weakest stimulus intensity felt by patients in three out of six stimulations. Surface-recording electrodes were attached using the belly-tendon method. Patients were instructed to maintain maximal voluntary thumb abduction against resistance during the examination because maintaining constant muscle contraction such as $50 \%$ of maximal contraction [7] was difficult in cervical myelopathy due to the involvement of the fasciculus cuneatus [8]. Stimulation was delivered after maximal voluntary contraction over five seconds [6]. This procedure was repeated five times out of consideration for patient fatigue and discomfort, with the inter-trial interval varying randomly between 10 and $20 \mathrm{~s}$. Five single sweeps of $500 \mathrm{~ms}$ in duration were recorded with the filter set at 20 and $5000 \mathrm{~Hz}$. CSP testing was performed using standard electrodiagnostic equipment (Neuropack S1; Nihon Koden; Tokyo, Japan).

CSP was defined as an absence or a clear reduction (the amplitude not exceeding $100 \mu \mathrm{V}$ ) of voluntary electromyography activity: complete CSP as defined by Kofler $[6,9]$. Although the high reproducibility of CSP testing has been reported on $[10,11]$, latencies and duration vary in each trace. Therefore, we firstly marked the CSP onset and end latency, secondly calculated the duration of each trace, and then determined the mean values of five responses. As the end of CSP is influenced by the onset of CSP and its duration, we reported the onset latency and the duration of CSP. When no visible CSPs were recorded for more than two out of the five trials, the series of trials was categorized as 'CSP absent'. The standard value of CSP was defined according to normal values reported in previous DCM studies $[6,12]$. Abnormal findings were as follows: delayed onset latency $>88.6 \mathrm{~ms}$, shortened duration $<28.5 \mathrm{~ms}$, and the absence of CSP. Because the index fingertip and APB muscle were considered to represent the C6 dermatome and C8, Th1 myotome [13], respectively, patients with cervical cord compression at and below the C4-5 spinal level were included in this study. The Japanese Orthopaedic Association (JOA) score was used for the functional evaluation. The JOA score is a 17-point scale that indicates the severity of cervical myelopathy based on sensorimotor and bladder function [14] (Table 1). Pain sensation was tested using pinprick perception as a part of JOA sensory score.

The participants in this prospective study provided informed consent, and this study was approved by the institutional review board (study no. ERB-102734).
Table 1 Functional scoring system for cervical myelopathy (Adapted from Japanese Orthopaedic Association [14])

\begin{tabular}{|c|c|c|}
\hline Function & Score & Remarks \\
\hline \multirow{5}{*}{$\begin{array}{l}\text { Motor function of } \\
\text { upper limbs }\end{array}$} & 0 & Unable to feed oneself \\
\hline & 1 & $\begin{array}{l}\text { Unable to handle chopsticks } \\
\text { but able to eat with a spoon }\end{array}$ \\
\hline & 2 & $\begin{array}{l}\text { Handle chopsticks with much } \\
\text { difficulty }\end{array}$ \\
\hline & 3 & $\begin{array}{l}\text { Handle chopsticks with slight } \\
\text { difficulty }\end{array}$ \\
\hline & 4 & Normal finger dexterity \\
\hline \multirow{5}{*}{$\begin{array}{l}\text { Motor function of } \\
\text { lower limbs }\end{array}$} & 0 & Chairbound \\
\hline & 1 & Requires walking aids \\
\hline & 2 & $\begin{array}{l}\text { Needs support when going up } \\
\text { and down stairs }\end{array}$ \\
\hline & 3 & $\begin{array}{l}\text { Capable of fast walking but } \\
\text { with some difficulty }\end{array}$ \\
\hline & 4 & Normal walking ability \\
\hline \multirow{3}{*}{$\begin{array}{l}\text { Sensory function of upper } \\
\text { limbs, lower limbs, and trunk }\end{array}$} & 0 & Severe sensory loss \\
\hline & 1 & Mild sensory loss \\
\hline & 2 & Normal \\
\hline \multirow[t]{4}{*}{ Sphincter function } & 0 & Retention and/or incontinence \\
\hline & 1 & $\begin{array}{l}\text { Sense of retention and/or } \\
\text { incomplete continence }\end{array}$ \\
\hline & 2 & Retardation and/or pollakiuria \\
\hline & 3 & Normal \\
\hline
\end{tabular}

The sensory score of "0" means no reference to pain

We examined 16 DCM patients who underwent surgery between April 2014 and July 2016 with a 12-month followup. DCM pathology included 13 cases of cervical spondylotic myelopathy (CSM), two cases of ossification of the posterior longitudinal ligament, and one case of cervical disc herniation (Table 2). All patients neurologically demonstrated progressive myelopathy with a varying degree of impaired sensorimotor function in both upper and lower extremities and bladder dysfunction. CSPs were recorded at four time-points: before surgery, and at 3, 6, and 12 months after surgery. The frequency of abnormal CSP findings was evaluated. Serial changes in the onset latency and duration were also examined. As the nominal variables of CSP, except for absent CSP, coexist with the continuous variables: measured values of latency and duration both had a non-normal distribution. The McNemar test was first used for the nominal variables to assess statistical difference between before and twelve months after surgery and the Friedman test with Bonferroni correction was used secondly for continuous variables. The JOA scores among CSP categories at before and 12 months after surgery were 
Table 2 Patients' demographic data

\begin{tabular}{|c|c|c|c|c|c|c|}
\hline $\mathrm{Pt}$ & Age & Gender & Diagnosis & $\begin{array}{l}\text { Stenosis } \\
\text { levels }\end{array}$ & $\begin{array}{l}\text { Levels of } \\
\text { intramedullary } \\
\text { hyperintensity } \\
\text { changes }\end{array}$ & $\begin{array}{l}\text { Operative } \\
\text { procedure }\end{array}$ \\
\hline 1 & 70 & M & OPLL & C3-5 & C4-5 & LP \\
\hline 2 & 66 & M & OPLL & C3-5 & C3-6 & LP \\
\hline 3 & 75 & $\mathrm{~F}$ & CSM & C5-7 & C6-7 & $\begin{array}{l}\text { ACDF } \\
\text { C6-7 }\end{array}$ \\
\hline 4 & 83 & $\mathrm{~F}$ & CSM & C3-7 & $\mathrm{C} 4-5$ & LP \\
\hline 5 & 62 & M & CSM & C3-7 & C3-4, 5-6 & LP \\
\hline 6 & 57 & $\mathrm{~F}$ & CSM & C5-7 & none & LP \\
\hline 7 & 72 & M & CSM & C4-5 & C4-5 & $\begin{array}{l}\text { ACDF } \\
\text { C4-5 }\end{array}$ \\
\hline 8 & 57 & $\mathrm{~F}$ & CSM & C4-6 & C4-5 & LP \\
\hline 9 & 52 & F & CSM (RA) & C5-6 & none & LP \\
\hline 10 & 67 & M & CSM & C4-7 & C4-5 & LP \\
\hline 11 & 63 & M & CSM & C4-6 & C4-5 & LP \\
\hline 12 & 60 & M & CSM & C4-6 & C5-6 & LP \\
\hline 13 & 63 & $\mathrm{~F}$ & CSM & C4-5 & C4-5 & LP \\
\hline 14 & 59 & $\mathrm{~F}$ & CSM & C4-6 & C4-6 & LP \\
\hline 15 & 41 & M & $\mathrm{CDH}$ & C5-6 & C5-6 & $\begin{array}{l}\text { ACDF } \\
\text { C5-6 }\end{array}$ \\
\hline 16 & 73 & M & CSM & C4-7 & C5-6 & LP \\
\hline
\end{tabular}

OPLL ossification of posterior longitudinal ligament, CSM cervical spondylotic myelopathy, $R A$ rheumatoid arthritis,

$C D H$ cervical disc herniation, $L P$ laminoplasty, $A C D F$ anterior cervical discectomy with fusion

assessed using the Kruskal-Wallis test with Bonferroni correction. These scores taken at the four time points were analyzed using Friedman test with Bonferroni correction. All statistical analyses were performed with EZR (Saitama Medical Center, Jichi Medical University, Saitama, Japan), which is a graphical user interface for $\mathrm{R}$ (The $\mathrm{R}$ Foundation for Statistical Computing, Vienna, Austria) [15]. $P<0.05$ was considered statistically significant.

\section{Results}

CSP findings and JOA scores of all patients are listed in Tables $3 \& 4$ and Fig. 1. CSP testing was conducted on 31 hands from 16 patients. Fifteen patients underwent CSP testing on both hands. Due to severe weakness (manual muscle testing $=3$ ) of the right APB muscle, one patient underwent CSP testing on only the left hand.

Table 3 showed the total JOA scores, CSP onset latency and its duration throughout the study period. The median (25-75\% percentiles) total JOA scores at before surgery, 3 , 6 , and 12 months after surgery were 8.5 (7.6-10.4), 13.5 (10.5-13.8), $15.3(10.6-16)$ and 15.3 (12.5-16.4), respectively. Clinical severity measured by the JOA score significantly improved after surgery $(P=0.0028,0.0027$ and 0.0028 at 3,6 , and 12 months after surgery compared to before surgery). The median (25-75\% percentiles) preoperative upper extremity motor and sensory scores were 2 (2-2) and $0.5(0.5-1)$, respectively. The motor scores of upper extremity scores at three, six and twelve months after surgery were $3.5(3-4), 4(3-4)$, and $4(3-4)$, respectively $(P=0.0030,0.0027$, and 0.0019 compared with before surgery). In addition, the sensory scores of the upper extremity at the same three time points were $0.5(0.5-1), 1$ $(1-1.5)$, and $1(1-1.5)$, respectively $(P=0.041,0.009$, and 0.0032 compared to before surgery). Eleven patients $(68.8 \%)$ fully recovered upper-extremity motor function, whereas only one patient $(6.3 \%)$ had the full score of the upper-extremity sensory function twelve months after surgery. Both hypalgesia and hypesthesia were observed in all patients before surgery and in all but one (patient no. 7) twelve months after surgery.

The distribution of CSP classification before surgery and twelve months after surgery were shown in Table 4 to demonstrate the transitions between each category during the study period. Preoperatively, normal CSPs were observed in five hands (16.1\%). While abnormal CSP findings were seen in 26 hands (83.9\%) consisting of one or both hands of all patients; absent CSPs were observed in eight hands $(25.8 \%)$ and delayed onset latencies, which were the most prevalent abnormal findings, were observed in 18 hands $(58.1 \%)$. Twelve months after surgery, six hands (19.4\%) including four hands with pre-operative delayed onset latency showed normal CSPs. Absent CSPs were observed in nine hands (29\%) including three hands with preoperative present CSPs. Delayed onset latency recovered to the normal range in four hands, whereas latency and/ or duration abnormality still existed in the rest of the hands. The distribution of normal and absent CSPs before surgery and 12 months after surgery did not show any significant difference, respectively $(P=1$ and $P=1)$. The frequency of abnormal findings, except for the absent CSPs, also did not change between before surgery and 12 months after surgery $(P=0.77)$. Moreover, the measured values of onset latency and duration of CSP did not change throughout the four time points $(P=0.60$ and 0.09$)$. (Table 3 and Fig. 1)

JOA total \& upper limb scores before surgery in each CSP category were as follows; $8(6.3-8.0)$ and 2.5(2-2.8) in normal CSPs, 10(8-10.5) and 3(2.5-3.5) in onset delay, 8.3(5.8-11.3) and 3(2.6-3.5) in onset delay with shortened duration, and 8.3(5.8-11.3) and 3(2.6-3.5) in absent CSPs. Out of all the before surgery categories, JOA total \& upper limb scores showed no significant difference $(P=0.23$ and 0.09$)$. JOA total \& upper limb scores twelve months after surgery were as follows; $13.8(8-16)$ 
Table 3 JOA scores and CSP findings before and after surgery

\begin{tabular}{|c|c|c|c|c|c|c|c|c|c|c|c|c|c|}
\hline \multirow[t]{2}{*}{$\mathrm{Pt}$} & \multicolumn{4}{|c|}{ JOA score } & & \multicolumn{4}{|c|}{ CSP onset latency (ms) } & \multicolumn{4}{|c|}{ CSP duration (ms) } \\
\hline & pre-op & p-o3m & p-o6m & $\mathrm{p}-\mathrm{o} 12 \mathrm{~m}$ & & pre-op & p-o3m & $\mathrm{p}-\mathrm{o} 6 \mathrm{~m}$ & $\mathrm{p}-\mathrm{o} 12 \mathrm{~m}$ & pre-op & $\mathrm{p}-\mathrm{o} 3 \mathrm{~m}$ & p-o6m & p-o12m \\
\hline \multirow[t]{2}{*}{1} & 8 & 10.5 & 10.5 & 12.5 & $\mathrm{R}$ & 85.4 & 92.8 & 98.6 & 92 & 35.4 & 18.4 & 25 & 26.8 \\
\hline & & & & & $\mathrm{L}$ & 90 & 83.2 & 88.6 & 87.6 & 35 & 24.8 & 15 & 27.2 \\
\hline \multirow[t]{2}{*}{2} & 5.5 & 10 & 9 & 10 & $\mathrm{R}$ & absent & absent & absent & absent & absent & absent & absent & absent \\
\hline & & & & & $\mathrm{L}$ & absent & absent & absent & absent & absent & absent & absent & absent \\
\hline \multirow[t]{2}{*}{3} & 11.5 & 14 & 15.5 & 16.5 & $\mathrm{R}$ & absent & 97.2 & 95.8 & 89.2 & absent & 15.2 & 16.6 & 37.6 \\
\hline & & & & & $\mathrm{L}$ & absent & 103.4 & 124 & absent & absent & 15.2 & 7.2 & absent \\
\hline \multirow[t]{2}{*}{4} & 4.5 & 8 & 10 & 8 & $\mathrm{R}$ & 78.8 & 92 & 88.6 & 88.6 & 57.2 & 47 & 43.2 & 67.6 \\
\hline & & & & & $\mathrm{L}$ & 90 & 87.2 & 87.4 & 87.2 & 57 & 44 & 60.6 & 61.8 \\
\hline \multirow[t]{2}{*}{5} & 10.5 & 13.5 & 14 & 14 & $\mathrm{R}$ & 115.8 & 106.4 & 107 & 119.8 & 31.8 & 40.8 & 40 & 28.6 \\
\hline & & & & & $\mathrm{L}$ & absent & absent & 104.2 & 103.6 & absent & absent & 20.2 & 20.2 \\
\hline \multirow[t]{2}{*}{6} & 11 & 16 & 16.5 & 16.5 & $\mathrm{R}$ & 97.6 & 85 & 101 & 93.2 & 44.4 & 35.2 & 13.6 & 22.8 \\
\hline & & & & & $\mathrm{L}$ & 106.8 & 93.4 & 87.4 & 86.6 & 25.6 & 24.6 & 23.8 & 24.8 \\
\hline \multirow[t]{2}{*}{7} & 10 & 15 & 15.5 & 17 & $\mathrm{R}$ & 110.4 & 108.4 & 95.6 & 103.8 & 69.8 & 22.2 & 24 & 19.2 \\
\hline & & & & & $\mathrm{L}$ & 105.8 & 97.6 & 97 & 100 & 36.4 & 36.6 & 22.4 & 22.4 \\
\hline \multirow[t]{2}{*}{8} & 8 & 13 & 16 & 15 & $\mathrm{R}$ & 82.4 & 87.8 & 82.2 & 85.4 & 69.8 & 27.6 & 32.6 & 45.6 \\
\hline & & & & & $\mathrm{L}$ & 92.4 & 91 & 95 & 101.2 & 42.4 & 18.4 & 19.6 & 25 \\
\hline \multirow[t]{2}{*}{9} & 8 & 15 & 13.5 & 12.5 & $\mathrm{R}$ & 78.8 & 91.6 & 95.2 & 94.2 & 52 & 24 & 22.8 & 26.8 \\
\hline & & & & & $\mathrm{L}$ & 94.8 & 95.2 & 90.2 & 86.2 & 29.2 & 12.2 & 31.8 & 31.6 \\
\hline 10 & 10.5 & 16.5 & 16.5 & 16.5 & $\mathrm{~L}$ & 90.6 & 93.2 & 100.6 & 115.8 & 27 & 34 & 36.8 & 16.6 \\
\hline \multirow[t]{2}{*}{11} & 8 & 16 & 16 & 16 & $\mathrm{R}$ & 103 & 103 & 92.8 & 93.4 & 61.6 & 43.8 & 51.6 & 49 \\
\hline & & & & & $\mathrm{L}$ & 86.2 & 85.4 & 81.8 & 90.2 & 63.6 & 54.6 & 56 & 51.8 \\
\hline \multirow[t]{2}{*}{12} & 10 & 13.5 & 15.5 & 15.5 & $\mathrm{R}$ & 96.4 & absent & 110.8 & absent & 24.4 & absent & 13.4 & absent \\
\hline & & & & & $\mathrm{L}$ & 109 & 105.2 & 103 & absent & 33.6 & 21.4 & 18.8 & absent \\
\hline \multirow[t]{2}{*}{13} & 10 & 13.5 & 15 & 15.5 & $\mathrm{R}$ & absent & 91.8 & absent & absent & absent & 40.4 & absent & absent \\
\hline & & & & & $\mathrm{L}$ & 107.8 & 109.6 & 108.6 & 107.4 & 33.6 & 33.2 & 26.4 & 20.8 \\
\hline \multirow[t]{2}{*}{14} & 7.5 & 10.5 & 11 & 12.5 & $\mathrm{R}$ & 88.8 & 84.2 & 84.2 & 91 & 27.8 & 30 & 30 & 23.2 \\
\hline & & & & & $\mathrm{L}$ & 90.6 & 89.6 & 84.2 & absent & 21.4 & 21.2 & 30 & absent \\
\hline \multirow[t]{2}{*}{15} & 9 & 16 & 16 & 16 & $\mathrm{R}$ & 93.4 & 80.2 & 78.8 & 74.2 & 9.4 & 20.8 & 28.6 & 33.4 \\
\hline & & & & & $\mathrm{L}$ & 91 & 74.8 & 69 & 64.8 & 18.4 & 41.6 & 51.2 & 55.8 \\
\hline \multirow[t]{2}{*}{16} & 6.5 & 9 & 9 & 8 & $\mathrm{R}$ & absent & 97 & 90.2 & absent & absent & 60 & 43.8 & absent \\
\hline & & & & & $\mathrm{L}$ & absent & absent & absent & absent & absent & absent & absent & absent \\
\hline
\end{tabular}

JOA score Japanese Orthopaedic Association score, Pre-op before surgery, $P$-O3M 3 months after surgery, $P$-O6M 6 months after surgery, $P$-O12M 12 months after surgery, CSP cutaneous silent period, normal range of CSP onset latency: 63.6-88.6 ms, normal range of CSP duration: 28.5-68.9 ms

and 4.3(3.5-5) in normal CSPs, 16(14.5-16.4) and $5(5-5.4)$ in onset delay, $14.5(12.5-16.5)$ and 5.3(5-5.5) in shortened duration, 15.3(12.5-16.6) and 5.3(4.4-5.6) in onset delay with shortened duration, and 12.5(9-15.5) and 5(4-5.5) in absent CSPs. Similarly, out of all the 12 months post-surgery categories, JOA total \& upper limb scores also showed no significant difference $(P=$ 0.25 and 0.17$)$. The number of paired JOA scores before and twelve months after surgery in each CSP category were as follows: two in normal CSPs, two in onset delay, two in onset delay with shortened duration, and six in absent CSPs. Due to the small number in each category,
JOA total \& upper limb scores before and after surgery were not statistically examined.

An illustrative case (Figs. 2a, b)

A 72-year-old male patient (patient no. 7) presenting with progressive bilateral hand numbness and gait disturbance was referred to our institution. Pre-operative MRI demonstrated cord compression and intramedullary signal changes at C4-5 due to spondylosis (Fig. 2a). He underwent C4-5 anterior cervical discectomy with fusion. His JOA score had recovered fully twelve months after surgery. However, the CSP onset delay remained throughout the study period (Fig. 2b). 
Table 4 The transition of CSP classification before and 12 months after surgery

\begin{tabular}{|c|c|c|c|c|c|c|c|}
\hline & & \multicolumn{5}{|c|}{ Twelve months after surgery } & \multirow{2}{*}{$\begin{array}{l}\text { Total number } \\
\text { of hands }\end{array}$} \\
\hline & & Normal & $\begin{array}{l}\text { Onset } \\
\text { delay }\end{array}$ & $\begin{array}{l}\text { Shortened } \\
\text { duration }\end{array}$ & $\begin{array}{l}\text { Onset delay + } \\
\text { shortened } \\
\text { duration }\end{array}$ & Absent & \\
\hline \multirow[t]{5}{*}{ Before surgery } & Normal & 2 & 1 & 0 & 2 & 0 & 5 \\
\hline & Onset delay & 2 & 2 & 1 & 5 & 1 & 11 \\
\hline & Shortened duration & 0 & 0 & 0 & 0 & 0 & 0 \\
\hline & Onset delay + shortened duration & 2 & 0 & 1 & 2 & 2 & 7 \\
\hline & Absent & 0 & 1 & 0 & 1 & 6 & 8 \\
\hline \multicolumn{2}{|c|}{ Total number of hands } & 6 & 4 & 2 & 10 & 9 & 31 \\
\hline
\end{tabular}

The numbers represented the number of hands

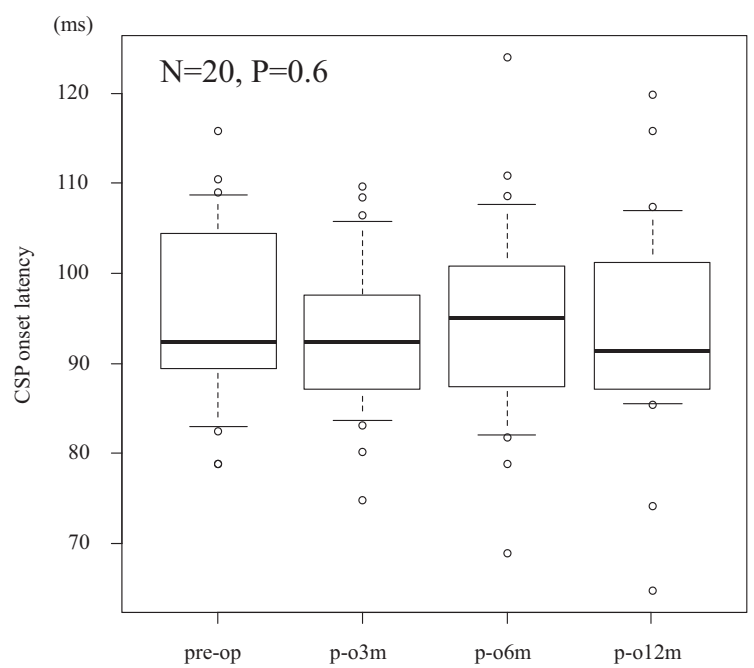

Fig. 1 Serial changes of the onset latency and duration of CSP. Graphs on the left and right respectively show the onset latency and duration at

\section{Discussion}

The incidence of pre-operative CSP abnormalities in DCM patients' hands was $84 \%$, which was equivalent to those reported in previous studies $[6,12]$. The CSP testing could sensitively detect the spinal cord dysfunction in DCM. However, CSP did not change significantly before and after surgery whereas the JOA score recovered in all patients. The results from this study failed to demonstrate an association between CSP changes and functional recovery after DCM surgery.

CSP is mediated by afferent small diameter A-delta fibers and inhibitory spinal interneurons suppressing alfa motor neuron activity. Ascending impulses elicited by painful fingertip stimulation travel along A-delta fibers and enter the spinal cord through the posterior horn. Then, the impulse is relayed synaptically to propriospinal projections near the central canal that suppress motor nuclei activity [9]. Preserved CSPs were reported in cervical radiculopathy [16] and cervical root avulsion [17]. On the other hand,

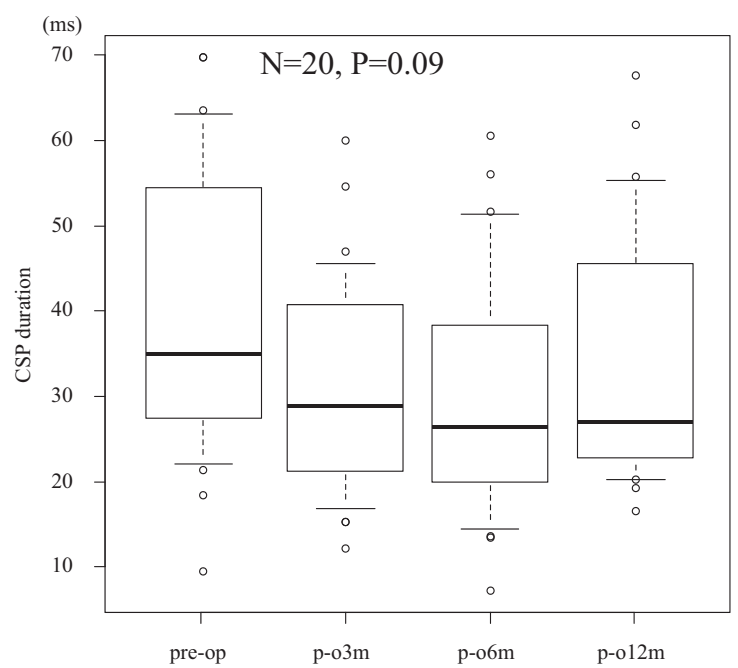

four time points. Both the onset latency and duration displayed no significant change among these four time points

abnormal CSP findings have been reported in syringomyelia and DCM [5, 6]. Thus, the spinal cord plays a crucial role in generating CSP. The variety of pathobiological changes in DCM including reduced spinal cord blood flow, interneuronal network loss, and neuronal cell death has been reported [18]. Structural changes in neurons and axons could explain the persistent CSP abnormalities due to abnormal signal processing in the spinal cord. The fact that the distribution of CSP categories did not change between before and 12 months after surgery implies irreversible damage to the spinal cord. A strong correlation between CSP abnormalities and spinothalamic dysfunction was reported in a cross-sectional study in DCM patients [6]. The CSP abnormalities and hand hypalgesia indicating spinothalamic dysfunction were both observed in all 16 patients before surgery. Furthermore, 14 patients $(87.5 \%)$ and 15 patients $(93.8 \%)$ respectively showed CSP abnormalities and hand hypalgesia 12 months after surgery. Although these results were consistent with the association between CSP abnormalities and spinothalamic dysfunction, 
Fig. 2 a Left: MRI delineated the most prominent cord compression at $\mathrm{C} 4-5$ before surgery (arrow). Right: The cord compression at $\mathrm{C} 4-5$ improved with some residual intramedullary signal change (arrow). b JOA scores improved to the full score twelve months after surgery, whereas, the averaged wave showed that the onset latency and duration did not change throughout the one-year period after surgery

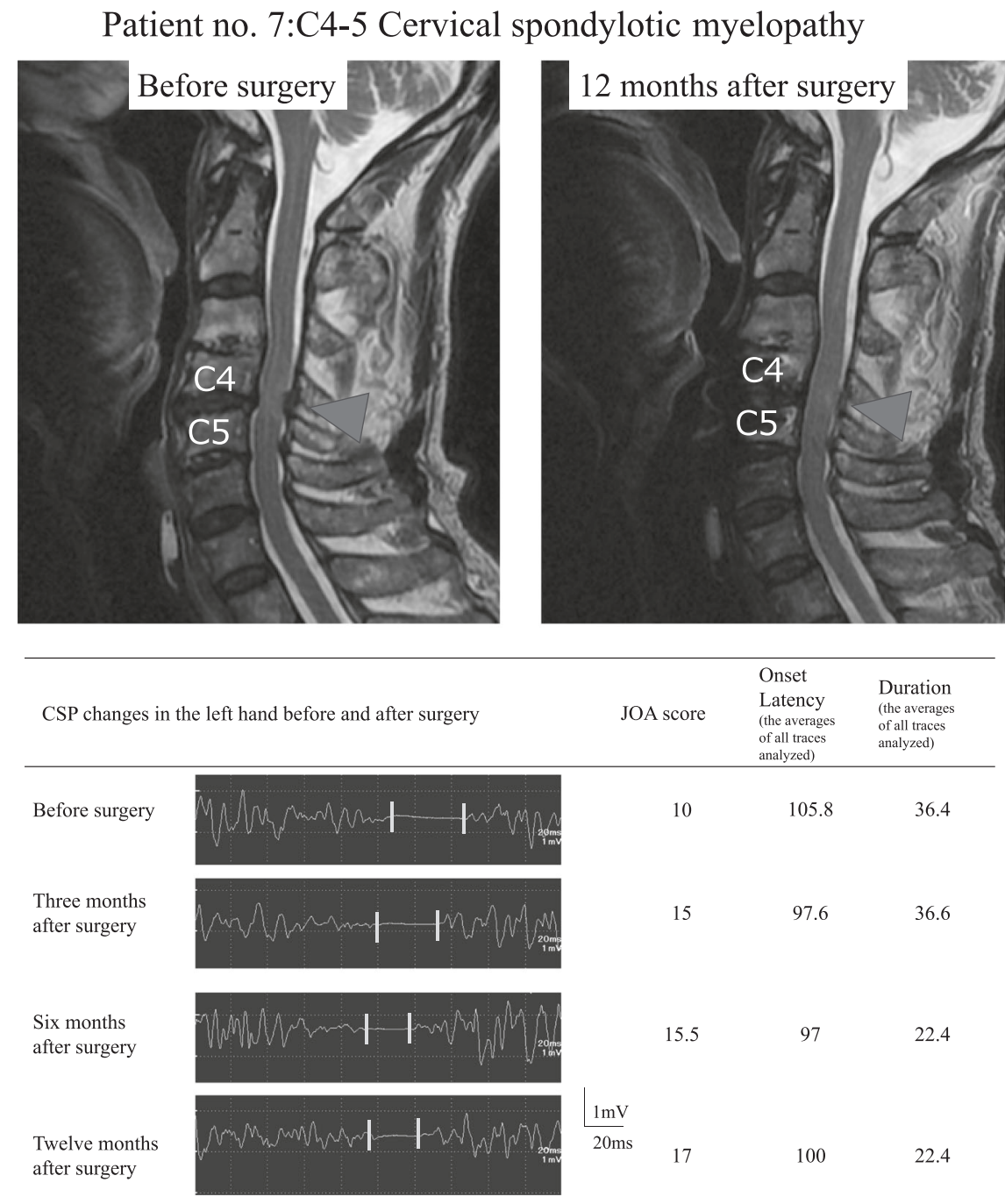

abnormal CSPs still existed even in the presence of full recovery of hand sensory impairment (an illustrative case). As there have been reports of spinothalamic dysfunction without any sensory dysfunction in cervical myelopathy $[6,19]$, the postoperative CSP abnormalities without hand hypalgesia may reflect the asymptomatic spinothalamic dysfunction.

The JOA score is a functional measure based on activities of daily living [14]. Since the postoperative functional recovery is well defined, the JOA score and its western version, the modified JOA score, are widely used in clinical practice [20]. However, we observed a discrepancy between JOA score recovery and CSP recovery in this study. JOA score recovery without CSP recovery appears to be explained by the following reasons: (1) the neural function less reflected in CSP such as motor or sensory spinal tract function contributes more to the JOA score. The reduction of central motor conduction time and the latency shortening of somatosensory-evoked potential were reported to show a postoperative functional recovery of the corticospinal tract
[21] and dorsal column [22], respectively; (2) abnormal CSP findings were observed even in mild cervical myelopathy [6]. Since few patients had full JOA score recovery, abnormal CSP findings might remain after surgery; (3) the compensatory mechanism obscures the residual spinal cord dysfunction. A recent report showed that the brain compensated for spinal cord dysfunction [23]. Thus, CSP alone could not serve to monitor the post-operative functional improvement. However, DCM patients demonstrate a variety of sensorimotor symptoms in hands. CSP which reflects the integrity of the hand sensorimotor coordination can complement the functional evaluation of DCM.

Although this study provided new evidence on the characteristics of CSP for clarifying spinal cord dysfunction, the following limitations should be clarified in future studies. The reported methods in previous studies for CSP testing varied from one study to the next. We mainly focused on the changes in complete CSP: the absence or the clear reduction of voluntary EMG activity. Visual inspection was used to evaluate complete CSP in a similar manner 
to preceding studies in DCM patients $[6,9,12]$. However, when there were no visible CSPs in more than two out of five trials, we evaluated it as 'CSP absent' in this study. This rule was applied to nine $(34.6 \%)$ out of 26 "CSP absent" hands during the study period. In these cases, CSPs in the residual traces were unfortunately abolished. A CSP evaluation such as an amplitude reduction below $80 \%$ of pre-stimulation levels [24] can detect incomplete CSP in some cases where CSP was absent in this study. In addition, CSP measurement using the rectified EMG traces [24, 25] also can evaluate the exact quantification of latencies, and duration in the presence of incomplete CSP. As both the definition and the measurement method of CSP used in this study could not evaluate incomplete CSP, a more detailed analysis can allow for the improved detection of CSP changes.

In future, investigating the association between CSP changes before and after surgery and other neurophysiological measures such as motor-evoked potentials and somatosensory-evoked potentials or other physical functional measures including "The Graded and Redefined Assessment of Strength, Sensibility, and Prehension (GRASSP)" [26] will facilitate our understanding of DCM pathophysiology and the mechanism of functional recovery.

In summary, abnormal CSP findings such as a delay in onset latency, shortened duration, and CSP absence persist after surgery despite JOA score recovery. Although abnormal CSP findings play a role in detecting spinal cord dysfunction, CSP alone might not serve to monitor gross functional improvement after surgery for DCM. The results of this study provide insight into postoperative neural recovery in DCM.

\section{Data archiving}

The datasets generated and/or analyzed during the current study are available from the corresponding author upon request.

Author contributions NT contributed to the planning of this research project, data collection, data analysis and was the main author of this manuscript. KK, YK, MK, RT and MI contributed to the planning of the project, data analysis and revision of the manuscript.

\section{Compliance with ethical standards}

Statement of ethics The participants in this prospective study provided informed consent, and this study was approved by the institutional review board (study no. ERB-102734).

Conflict of interest The authors declare that they have no conflict of interest.

Publisher's note: Springer Nature remains neutral with regard to jurisdictional claims in published maps and institutional affiliations.

\section{References}

1. Nouri A, Tetreault L, Dalzell K, Zamorano JJ, Fehlings MG. The relationship between preoperative clinical presentation and quantitative magnetic resonance imaging features in patients with degenerative cervical myelopathy. Neurosurgery. 2017;80:121-8.

2. Tetreault L, Kopjar B, Cote P, Arnold P, Fehlings MG. A clinical prediction rule for functional outcomes in patients undergoing surgery for degenerative cervical myelopathy: analysis of an international prospective multicenter data set of 757 subjects. J bone Jt Surg Am Vol. 2015;97:2038-46.

3. Kato F, Yukawa Y, Suda K, Yamagata M, Ueta T. Normal morphology, age-related changes and abnormal findings of the cervical spine. Part II: Magnetic resonance imaging of over 1,200 asymptomatic subjects. Eur Spine J. 2012;21:1499-507.

4. Leis AA, Kofler M. Silent period. In: Aminoff MJ and Daroff RB, editors. Encyclopedia of the neurological sciences, 2nd ed., Vol. 4. Oxford: Academic Press; 2014. p. 164-8.

5. Roser F, Ebner FH, Liebsch M, Dietz K, Tatagiba M. A new concept in the electrophysiological evaluation of syringomyelia. J Neurosurg Spine. 2008;8:517-23.

6. Stetkarova I, Kofler M. Cutaneous silent periods in the assessment of mild cervical spondylotic myelopathy. Spine. 2009;34: $34-42$.

7. Kofler M, Kumru H, Stetkarova I, Schindler C, Fuhr P. Muscle force up to $50 \%$ of maximum does not affect cutaneous silent periods in thenar muscles. Clin Neurophysiol. 2007;118:2025-30.

8. Akutagawa T, Tani T, Kida K, Tadokoro N, Enoki H, Nagano Y, et al. A new method for characterizing hand dysfunction in cervical spondylotic myelopathy: a preliminary study. Spinal Cord. 2016;54:221-5.

9. Kofler M, Kronenberg MF, Brenneis C, Felber A, Saltuari L. Cutaneous silent periods in intramedullary spinal cord lesions. J Neurol Sci. 2003;216:67-79.

10. Pullman SL, Ford B, Elibol B, Uncini A, Su PC, Fahn S. Cutaneous electromyographic silent period findings in brachial dystonia. Neurology. 1996;46:503-8.

11. Kofler M. Functional organization of exteroceptive inhibition following nociceptive electrical fingertip stimulation in humans. Clin Neurophysiol. 2003;114:973-80.

12. Lo YL, Tan YE, Dan YF, Leoh TH, Tan SB, Tan CT, et al. Cutaneous silent periods in the evaluation of cord compression in cervical spondylosis. J Neurol. 2007;254:14-9.

13. Chiba T, Konoeda F, Higashihara M, Kamiya H, Oishi C, Hatanaka Y, et al. C8 and T1 innervation of forearm muscles. Clin Neurophysiol. 2015;126:837-42.

14. Japanese Orthopaedic Association. Japanese Orthopaedic Association scoring system for cervical myelopathy (17-2 version and 100 version). Nippon Seikeigeka Gakkai Zasshi 1994;68:490-503.

15. Kanda Y. Investigation of the freely available easy-to-use software 'EZR' for medical statistics. Bone Marrow Transpl. 2013;48:452-8.

16. Leis AA, Kofler M, Stetkarova I, Stokic DS. The cutaneous silent period is preserved in cervical radiculopathy: significance for the diagnosis of cervical myelopathy. Eur Spine J. 2011;20:236-9.

17. Vasko P, Bocek V, Mencl L, Haninec P, Stetkarova I. Preserved cutaneous silent period in cervical root avulsion. J spinal cord Med. 2017;40:175-80.

18. Nouri A, Tetreault L, Singh A, Karadimas SK, Fehlings MG. Degenerative cervical myelopathy: epidemiology, genetics, and pathogenesis. Spine. 2015;40:E675-93.

19. Ulrich A, Min K, Curt A. High sensitivity of contact-heat evoked potentials in "snake-eye" appearance myelopathy. Clin Neurophysiol. 2015;126:1994-2003. 
20. Tetreault L, Nouri A, Kopjar B, Cote P, Fehlings MG. The minimum clinically important difference of the modified Japanese Orthopaedic Association Scale in patients with degenerative cervical myelopathy. Spine. 2015;40:1653-9.

21. Nakanishi K, Tanaka N, Kamei N, Ohta R, Fujioka Y, Hiramatsu $\mathrm{T}$, et al. Electrophysiological evidence of functional improvement in the corticospinal tract after laminoplasty in patients with cervical compressive myelopathy: clinical article. J Neurosurg Spine. 2014;21:210-6.

22. Ishida K, Tani T, Ushida T, Zinchk V, Yamamoto H. Recovery of spinal cord conduction after surgical decompression for cervical spondylotic myelopathy: serial somatosensory evoked potential studies. Am J Phys Med Rehabil / Assoc Acad Physiatr. 2003;82:130-6.
23. Zdunczyk A, Schwarzer V, Mikhailov M, Bagley B, Rosenstock $\mathrm{T}$, Picht $\mathrm{T}$, et al. The corticospinal reserve capacity: reorganization of motor area and excitability as a novel pathophysiological concept in cervical myelopathy. Neurosurgery. 2018;83: $810-8$.

24. Kofler M, Leis AA, Valls-Sole J. Cutaneous silent periods - Part 1: Update on physiological mechanisms. Clin Neurophysiol. 2019; 130:588-603.

25. Floeter MK. Cutaneous silent periods. Muscle Nerve. 2003;28: 391-401.

26. Velstra IM, Fellinghauer C, Abel R, Kalsi-Ryan S, Rupp R, Curt A. The graded and redefined assessment of strength, sensibility, and prehension version 2 provides interval measure properties. $\mathrm{J}$ Neurotrauma. 2018;35:854-63. 